KLEINE TEXTE FÜR VORLESUNGEN UND ÜBUNGEN HERAUSGEGEBEN VON HANS LIETZMANN

\title{
DIE KLEINEREN HISTORIKERFRAGMENTE AUF PAPYRUS
}

\author{
BEARBEITET \\ voN \\ F R. B I L A B E L
}

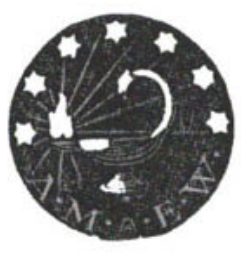

BONN

A. MARCUS UND E. WEBER'S VERLAG

I922 
Die vorliegende Sammlung der kleineren Historikerfragmente, die auf Papyrus erhalten sind, bezweckt, die Texte, welche sehr verstreut in heute zum Teil kaum mehr erschwinglichen Publikationen veröffentlicht sind, einem weiteren Kreise bequem zugänglich zu machen. Ausgeschlossen wurden die großen, in Sonderveröffentlichungen vorliegenden

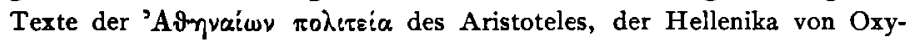
rhynchos und der Liviusepitome sowie auch die kleinen Stücke, die in Zitatenform im Didymoskommentar zu des Demosthenes Philippicae und in manchen anderen, wiedergewonnen Werken erhalten sind. Ebenso wurden die mancherlei bistorischen Nachrichten, die sich aus Biographien, Schultexten und ähnlichen Werken, ja selbst aus Dichtern, heben lassen, nicht aufgenommen, zumal sie an anderem Orte vorgelegt werden sollen. DaB Papyri der uns längst bekannten Historiker nicht berücksichtigt wurden, ist selbstverständlich. Dagegen bin ich in der Lage, zwei noch unveröffentlichte Fragmente zu bringen. Für die Überlassung des Berliner Stückes wie einer Photographie von Nr. 8 bin ich Herrn Professor Schubart, für die leihweise Übersendung des Sosylos der Würzburger Universitätsbibliothek zu aufrichtigem Danke verpflichtet.

Auf Wunsch des Verlages habe ich nur wirklich unsichere Buchstaben durch Punkte bezeichnet, dagegen von der Kenntlichmachung nicht ganz erhaltener, aber sicher zu ergänzender, durch untergesetzte Striche abgesehen. Von mir herrührende Ergänzungen sind mit B. gezeichnet.

Heidelberg, im Juni 1922.

$$
\text { Fr. Bilabel. }
$$

